\title{
Management of Cardiac Pacemakers in a Pregnant Patient
}

\author{
Sonal Grover1, Puja Sheth1, David E. Haines ${ }^{2}$, Mazhar Khan³ ${ }^{3}$ Bernard Gonik ${ }^{{ }^{*}}$ \\ ${ }^{1}$ Department of Obstetrics and Gynecology, Wayne State University School of Medicine, Detroit, USA \\ ${ }^{2}$ Department of Cardiovascular Medicine, Oakland University William Beaumont School of Medicine, Royal Oak, \\ USA \\ ${ }^{3}$ Department of Cardiology, Wayne State University School of Medicine, Detroit, USA \\ Email: BGonik@dmc.org, sgrove@med.wayne.edu
}

Received 5 January 2015; accepted 20 January 2015; published 23 January 2015

Academic Editor: Christos E. Constantinou, Stanford University Medical School, USA

Copyright (C) 2015 by authors and Scientific Research Publishing Inc.

This work is licensed under the Creative Commons Attribution International License (CC BY). http://creativecommons.org/licenses/by/4.0/

(c) (1) Open Access

\section{Abstract}

Introduction: Despite the increasing use of permanent cardiac pacemakers in a younger patient population, there are little data related to pregnancy. We present our experience in managing a pregnant patient with a pre-existing pacemaker and review the existing literature to establish management guidelines. Case: A 27-year-old G1 P0 presented for prenatal care in the first trimester of pregnancy. She had a past medical history of bradycardia, hypotension and syncope that required dual chamber cardiac pacemaker placement 6 years earlier, and one episode of left upper extremity venous thrombosis related to replacement of the pacemaker wire 4 years earlier. In the early second trimester, the patient began experiencing light-headedness and breathlessness with exertion. The rate settings of the pacemaker were increased with resolution of the patient's symptoms. The patient underwent primary cesarean section at 39 weeks gestation with delivery of a healthy term infant. Preoperative anesthesia consultation was obtained. The postoperative course was uneventful. Pre-pregnancy pacemaker settings were re-established after the postpartum period. Discussion: The current literature on managing pregnant patients with pre-existing pacemakers is quite limited. Such patients require a multidisciplinary approach to care. Normal physiologic changes in pregnancy may necessitate rate adjustments. Other than routine thromboprophylaxis, no other anticoagulation is needed. Route of delivery is generally based on obstetric indications. During surgery consider using bipolar electrocautery in place of unipolar electrocautery, to reduce electromagnetic interference. Also, the placement of the grounding pad should be as far away from the pacemaker as possible. It should be anticipated that the patient will return to her baseline cardiac status postpartum and therefore pacemaker settings can be adjusted accordingly.

\footnotetext{
${ }^{*}$ Corresponding author.
} 


\section{Keywords}

\section{Pacemaker, Pregnancy, Anticoagulants, Fetal Monitoring, Electrocardiography, Anesthesia, Antepartum}

\section{Introduction}

Despite the increasing use of permanent cardiac pacemakers in a younger patient population, there are little data related to pregnancy. Normal physiologic alterations of pregnancy need to be taken into account in the management of the pregnant woman with a pacemaker in place. Similarly, gestational events including the potential for surgical intervention require a basic knowledge of pacemaker technology and monitoring. We present a case of a patient with a pre-existing pacemaker who presented in pregnancy in order to illustrate pertinent issues in this regard.

\section{Case Report}

A 27-year-old G1 P0 presented for prenatal care in the first trimester of pregnancy. She had a significant past medical history of bradycardia, hypotension and syncope that required permanent DDD cardiac pacemaker placement 6 years earlier. One year after implant, she had failure of both atrial and ventricular leads secondary to lead-to-lead abrasion and insulation failure. The leads were replaced. She had one episode of left upper extremity venous thrombosis related to replacement of the pacemaker wire 4 years ago, that was treated with short term anticoagulation therapy. A thrombophilia work up revealed an MTHFR compound heterozygous gene mutation. No additional anticoagulation was administered. During the pregnancy the patient was placed on prenatal vitamins and folate supplementation. In the early second trimester, the patient began experiencing light-headedness and breathlessness with exertion. Pacemaker interrogation showed that the pacemaker was programmed in the DDD mode with a low rate of $60 \mathrm{ppm}$. She was predominantly atrial pacing at $60 \mathrm{ppm}$ with native AV conduction and entricular sensing. Her heart rate histogram showed relative chronotropic incompetence for a pregnant woman (Figure 1). The basal pacing rate was increased to $80 \mathrm{ppm}$ during the day and $70 \mathrm{ppm}$ during sleep, with resolution of the patient's symptoms. The remainder of the pregnancy progressed unremarkably. The patient underwent primary cesarean section at 39 weeks gestation with delivery of a healthy term infant. Preoperative anesthesia consultation was obtained. The postoperative course was uneventful. Pre-pregnancy pacemaker settings were re-established after the postpartum period.

\section{Discussion}

An increasing number of women with implanted pacemakers present to their obstetrician contemplating pregnancy or already pregnant. Reasons for this are multifaceted, but include improvements in cardiovascular surgery for congenital heart conditions, advancements in pacemaker technologies, and an expanding database that reassures the health care community that successful pregnancies can be accomplished with minimal adverse consequences [1]. Still, the current literature on this subject is quite limited and incomplete [2]-[4]. Recognizing that care of such patients requires a multidisciplinary approach, the obstetrician-gynecologist should be aware of the basic principles related to the care of these types of patients.

\section{Incidence}

The most common reason for pacemaker placement in a reproductive aged female patient is sinus node dysfunction followed by atrioventricular (AV) block [5] [6]. Other less common indications include neurocardiogenic syncope and iatrogenic causes such as AV node injury after ablation for supraventricular tachycardia. Figure 2 illustrates the American College of Cardiology/American Heart Association guidelines for implantation of pacemaker [7].

\section{Physiology of Pregnancy}

Pregnancy is associated with a variety of cardiovascular physiologic changes that may influence the need for 


\section{dln Diagnostics}

Date: $6 / 26 / 2012$

Time: 09:04

Art. rate histogram

Start

Duration

09:49

$05 / 15 / 2012$

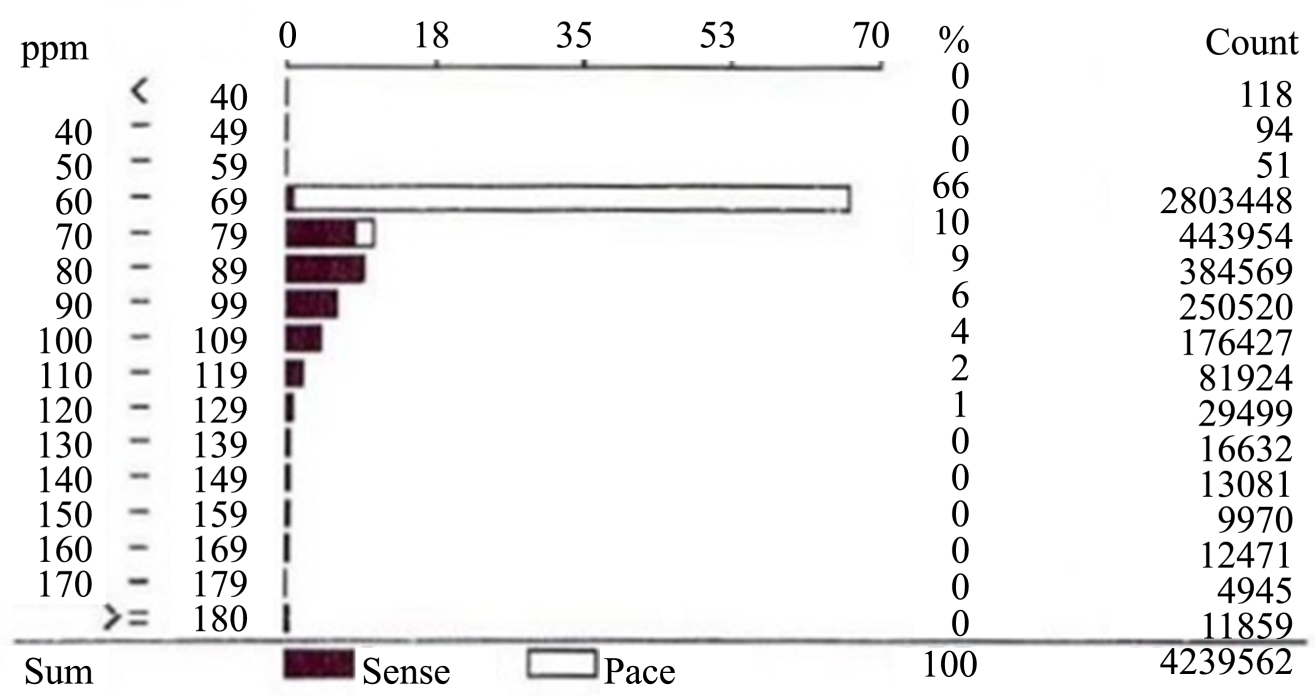

Figure 1. Histogram representation of time spent in heart rate ranges by deciles. The patient spent $66 \%$ of her time at the low rate of the pacemaker (60 - $69 \mathrm{bpm})$, and rarely exceeded $89 \mathrm{bpm}$. This indicates chronotropic incompetence, with an inappropriately low heart rate for a pregnant woman.

\section{GROUP 1: DEFINITE INDICATIONS FOR PACING:}

- Acquired complete atrioventricular (AV) block.

- Congenital complete heart block with severe bradycardia: ventricular rates $<50$ to $55 \mathrm{bpm}$ in an infant or ventricular rate $<70 \mathrm{bpm}$ when associated with congenital heart disease

- Symptomatic Mobitz II AV block.

- Symptomatic Mobitz I AV block.

- Symptomatic sinus bradycardia, in which the symptoms are clearly related to the bradycardia.

\section{GROUP 2: POSSIBLE INDICATIONS FOR PACING:}

- Asymptomatic type 1 second degree AV block at intra- or infra-His levels when found incidentally on EKG.

- First degree AV block when there is a hemodynamic compromise.

- Congenital complete heart block, beyond the first year of life, with an average heart rate $<50 \mathrm{bpm}$, or with abrupt pauses in the ventricular rate which are double or triple the basic cycle length.

- Bifascicular or trifascicular block accompanied by syncope.

- Asymptomatic MobitzII second-degree AV block.

- Symptomatic sinus bradycardia, in which there is not a clear association between the bradycardia and significant symptoms.

Figure 2. American College of Cardiology/American Heart Association guidelines for implantation of pacemaker.

pacemaker support, or alter the management of a patient already implanted with such a device. Blood volume normally increases during pregnancy, with an estimated $50 \%$ increase from baseline near term [8]. Cardiac output rises during the early weeks in pregnancy to about 30\% above non-pregnant levels, and remains there for the 
duration of the pregnancy [9]. Early on, this is primarily due to an increase in stroke volume, but later is also associated with an increased heart rate. A drop in cardiac output can be demonstrated late in gestation, mainly as a function of reduced venous return due to inferior vena cava compression by the enlarged uterus; left lateral positioning will minimize this effect. Reduced systemic vascular resistance is a regular feature of advancing pregnancy [9]. This presents clinically as a reduction in both systolic and diastolic blood pressure in the middle trimester of pregnancy, with a later return to pre-pregnancy values.

\section{Electrocardiographic Changes in Pregnancy}

As the pregnancy advances the growing gravid uterus elevates the diaphragm resulting is leftward deviation of the maternal heart in relation to the chest wall. This is reflected on the electrocardiogram (EKG), as shift of QRS axis to the left in the frontal plane [10]. Other EKG changes that have been reported are development of new arrhythmias, frequent sinus tachycardia with accompanying shortened PR and QT intervals, small Q waves and inverted P waves in lead III (abolished by inspiration), increased R/S ratio in leads V1 and V2, sagging of ST segments and inverted or flat $\mathrm{T}$ waves in lead III [11]-[15]. Figure 3 summarizes these EKG changes during pregnancy.

\section{Pacemaker Technology}

Many different types of pacemakers exist today, requiring a basic understanding of this technology. Pacemakers consist of 2 basic parts: the pulse generator, and electrode wires or leads. Permanent pacemaker leads are usually placed transvenously through the cephalic, axillary or subclavian veins. Pacemakers can be programmed externally with radio waves from a pacemaker programmer [16]. The North American Society of Pacing \& Electrophysiology (NASPE) and the British Pacing \& Electrophysiology Group (BPEG) have jointly established the nomenclature, known as the NBG (NASPE/BPEG Generic) code, to identify the variety of pacemakers (Table 1) [17]. It is based on 5 letters, the first letter denotes the chamber(s) being paced, the second letter refers to the chamber(s) in which sensing occurs, with "A" indicating atrium, "V" ventricle and "D" dual for both atrium and ventricle. The third position refers to the response of the pacemaker to a sensed event. The fourth letter indicates the presence or absence of rate modulation and the fifth letter reflects the potential and location of multisite pacing. The pacemakers are selected based on the specific abnormality present in the individual [1]. Our patient had a dual chamber pacemaker programmed in DDD mode, indicating that both atrial and ventricular chambers

\section{- QRS axis deviation}

- Small $Q$ and inverted $P$ wave in lead III (abolished by inspiration)

- ST segment and T-wave changes

- Frequent sinus tachycardia

- Development of new arrhythmias

Figure 3. Electrocardiographic changes during normal pregnancy.

Table 1. The Revised NASPE/BPEG generic pacemaker code.

\begin{tabular}{|c|c|c|c|c|c|}
\hline Position: & I & II & III & IV & V \\
\hline \multirow[t]{5}{*}{ Category: } & Chamber(s) Paced & Chamber(s) Sensed & Response to Sensing & Rate Modulation & Multisite Pacing \\
\hline & $\mathrm{O}=$ None & $\mathrm{O}=$ None & $\mathrm{O}=$ None & $\mathrm{O}=$ None & $\mathrm{O}=$ None \\
\hline & $\mathrm{A}=$ Atrium & $\mathrm{A}=$ Atrium & $\mathrm{T}=$ Triggered & $\mathrm{R}=$ Rate modulation & $\mathrm{A}=$ Atrium \\
\hline & $\mathrm{V}=$ Ventricle & $\mathrm{V}=$ Ventricle & $\mathrm{I}=$ Inhibited & & $\mathrm{V}=$ Ventricle \\
\hline & $\mathrm{D}=$ Dual $(\mathrm{A}+\mathrm{V})$ & $\mathrm{D}=$ Dual $(\mathrm{A}+\mathrm{V})$ & $\mathrm{D}=$ Dual $(\mathrm{T}+\mathrm{I})$ & & $\mathrm{D}=\operatorname{Dual}(\mathrm{A}+\mathrm{V})$ \\
\hline Munufacturers' designation only: & $\mathrm{S}=$ Single $(\mathrm{A}$ or $\mathrm{V})$ & $\mathrm{S}=$ Single $(\mathrm{A}$ or $\mathrm{V})$ & & & \\
\hline
\end{tabular}


were either sensed or paced if needed. Atrial activity was tracked and in the absence of ventricular activity a ventricular stimulus was delivered.

Further, pacemakers that are rate responsive allow for a pre-programmed adjustment to the heart rate [18]. Our patient had a rate responsive pacemaker, which is advantageous for patients with chronotropic incompetence because of its ability to increase rate in response to exercise, which becomes more vital as the pregnancy advances. Sensors for rate modulation are incorporated in the pacemaker and depending on pacemaker model respond to activity, minute ventilation or a combination of both. The alternative, a fixed rate pacemaker, is programmed at a set rate, and is unable to change with patient activity [18]. Hidaka et al. [19], reported their experience with fixed-rate pacemakers in pregnant patients and concluded their safe use, mostly because of the increase in stoke volume that occurs if the pacing rate if set correctly. The pacing rates in their study were 70 - 90 beats per minute, but they also stated that the optimal pacing rate was not investigated. Based on the historic literature, if a fixed rate device is used, empiric rates of between 60 to $120 \mathrm{bpm}$ have all been suggested [20]. Today, all modern pacers have rate responsive capabilities. The patient either has rate responsiveness turned on if they are chronotropically challenged, or off if they have intact sinus node function but have a problem like heart block. In that case, the pacer is "rate responsive" in that it tracks sinus rhythm/sinus tachycardia and paces the ventricle.

\section{Approach to Antenatal Management}

\subsection{Role of Preconception Counseling}

As some pregnant patients have pacemakers due to congenital heart defects, preconception counseling to discuss fetal risks for cardiac anomalies may need to be employed. It is well established that fetal risk for cardiac anomaly is 2-5 times greater if the affected patient is the mother (Table 2) [21]. Of note, the cardiac anomalies are not always the same as those of the parent. Additionally, some cardiac lesions may be a part of a larger syndromic diagnosis in the parents, and therefore genetic counseling may need to be expanded beyond cardiac concerns [22]. Importantly, several of these conditions have specific genetic markers that can be tested using either chorionic villus or amniocentesis-derived samples. Preconception counseling also allows for a thorough evaluation of the maternal cardiac status, with the opportunity to optimize her condition, preemptively modify pharmacologic agents appropriate for pregnancy, and deal with other comorbidities that may have an effect on pregnancy [23].

\subsection{Management during Pregnancy}

Usually patients with pacemakers tolerate the pregnancy well. The few reported maternal complications appeared to be isolated to patients with underlying structural heart disease [24]. Thaman et al. [24] reported their experience with 11 pregnant patients with pacemakers. Three of these patients, who had underlying structural heart disease, developed maternal complications. One patient developed cardiac decompensation in the third trimester and was induced at 38 weeks. The other developed recurrent palpitations secondary to a short run of atrial fibrillation. Both these patients had uneventful deliveries and postpartum courses. The third patient developed progressive right ventricular failure and had an intrauterine fetal death at 20 weeks gestation. Although these data suggest the need for more careful surveillance when a structural heart defect is associated with pacemaker usage, given the very limited nature of these reported events, a firm recommendation cannot be established.

With regard to routine care, co-management with the cardiology service is required. Either before the pregnancy or early in the first trimester, an EKG, echocardiogram and baseline pacemaker interrogation should be done. Device interrogation can provide information about pacemaker dependency. Pacemaker dependent patients may have no or very slow escape rhythms and require extra precautions during surgery. Throughout the pregnancy, attention should be paid to any new onset of symptoms such as palpitations, shortness of breath, syncope, seizure-like activity, dizziness, confusion, and exercise intolerance [25]. It may be difficult to distinguish between normal common pregnancy symptoms and mild degrees of cardiac dysfunction, requiring further evaluation and adjustments in pacing rate. Our patient began experiencing light-headedness and breathlessness with exertion, in the early second trimester. After cardiac evaluation the rate settings of the pacemaker were in creased with resolution of the patient's symptoms. 
Table 2. Recurrence risks for isolated congenital heart defects.

\begin{tabular}{cc}
\hline Affected Relative & Recurrent Risk For Affected Offspring (\%) \\
One affected Child & $1-3$ \\
Affected Parent (Father) & $1-5$ \\
Affected Parent (Mother) & $2.5-18$ \\
Two affected children & $5-10$ \\
\hline
\end{tabular}

\subsection{Use of Anticoagulants}

Pregnancy is considered a pro-thrombotic state due to the increase in coagulation factors. Levels of fibrinogen (Factor I), factors VII, VIII, IX, and X all increase by 50\% during pregnancy. In addition, activated protein C and S, inhibitors of coagulation, decrease during pregnancy [26]. Despite these recognized physiologic changes in pregnancy, routine anticoagulation is not typically recommended in patients with pacemakers, unless additional risk factors are identified. There have been a few cases of recurrent pulmonary emboli secondary to large thrombi formed along the pacemaker lead reported in the literature [27] [28]. Most of these cases responded well to anticoagulation with heparin when the symptoms presented. There is one reported case where the thrombi did not resolve with anticoagulation treatment, which required interventional cardiac surgery after an uncomplicated delivery [29]. Adequate data are lacking to firmly establish absolute clinical guidelines in the management of the patient with a pacemaker in place. Despite the absence of pharmacologic recommendations, prophylactic measures such as the use of pregnancy-specific support hose and avoiding situations that lead to lower extremity venous stasis should be empirically employed.

In cases where anticoagulation is required, heparin derivatives are preferred over warfarin as these former agents do not cross the placenta [30]. An exception may be in the patient with mechanical valves, where heparin use was associated with a higher incidence of valve thrombosis compared to warfarin [31]. This remains a controversy, and multiple empiric regimens have been suggested in these specific circumstances [32]. In one report, a patient on warfarin with an implanted pacemaker secondary to Ebstein's anomaly had an intrauterine fetal demise at 20 weeks [24]. The fetal autopsy showed evidence of warfarin embryopathy [4]. Warfarin use beyond 36 weeks of gestation might also be associated with an increased risk of both maternal and fetal hemorrhage [33].

\subsection{Delivery Route}

In terms of choosing a vaginal delivery versus a caesarean section for these patients, both methods have been advocated for in case reports [34] [35]. Generally speaking, delivering with a pre-existing pacemaker is a low risk event and not a contraindication for vaginal delivery. The decision regarding route of delivery should be based on the obstetric indications or other co-morbidities associated with the pregnancy [19] [26].

\subsection{Fetal Monitoring}

Pacemakers do not interfere with antepartum or intrapartum external fetal heart rate monitoring. This is because these are ultrasonographic modalities that do not compete electronically with the pacemaker device. During labor, internal fetal scalp electrodes are most commonly used to record fetal electrocardiographic signals. The typical fetal scalp electrode has notch filters that eliminate power line interference frequencies above $60 \mathrm{~Hz}$ and band-pass filters that omit frequencies $<30 \mathrm{~Hz}$ and $>100 \mathrm{~Hz}$, thus allowing only frequencies between $30-50 \mathrm{~Hz}$ to be picked [36] [37]. The maternal ECG signals are below $30 \mathrm{~Hz}$ [38] and are therefore selectively filtered out by these device features. However, there are some reports where the scalp electrode recorded the pulse from the maternal pacemaker rather than the fetal $\mathrm{R}$ wave during intrapartum monitoring. This happens when the maternal pacing artifact has higher voltage than the fetal R wave, as a result, maternal ECG signals instead of fetal R waves are detected by fetal scalp electrode. For this reason, manufacturers of fetal heart rate monitors specifically note that use of their instruments require extra caution during monitoring.

\subsection{Anesthesia and Pacemakers}

The anesthetic management of a pregnant patient with a pacemaker is also important to consider for delivery 
management. Anesthesia consultation early during the pregnancy is advised [1]. During the first stage of labor, cardiac output can increase by $12 \%$ from the baseline value and increases even further as labor continue. At full cervical dilation cardiac output increases by an average value of 34\% [39]. These changes in cardiac output can be attenuated with the use of epidural anesthesia [19] [40]. Further, performing the delivery in the lateral decubitus position is also recommended, as this position reduces rapid hemodynamic fluctuations during bearing down [41].

In patients undergoing cesarean delivery, the anesthesiologist must be aware of mode of pacing, date of implantation and durability of the pacemaker batteries [42]. He should be able to recognize early signs of reduced cardiac output and any pacemaker dysfunction on ECG. Additionally, any electrolyte imbalance must be corrected before anesthesia as both hypokalemia or hyperkalemia can alter the pacing threshold [43]. While selecting the type of anesthesia for surgery, it is best to avoid any maternal hypotension as it can compromise uteroplacental blood flow [44]. For this reason epidural anesthesia is preferred over spinal anesthesia as latter is more often associated with maternal hypotension and subsequent fetal bradycardia [40]. This especially important in patients with pacemakers who may not generate a tachycardic response to hypotension associated with conduction anesthesia [45]. Baron et al. [46] did not find any difference in maternal heart rate before and after the epidural anesthesia. Further, adequate prior hydration and vasopressors should be used to minimize hemodynamic changes associated with regional anesthesia [42].

During cesarean delivery, only bipolar electrocautery should be used, and in very short bursts, to avoid interference pacemaker output and inappropriate resetting of the device [47]. Inhibition of output due to interference from electrocautry may lead to asystole in a pacemaker dependent patient. Reprogramming of the pacemaker to an asynchronous mode is protective against electromagnetic interference and is generally only done for pacemaker dependent patients. If changes in pacemaker programming are made before surgery, it is important to program the device back to initial settings after surgery. As a routine precaution, the grounding plate for the cautery system should be placed as close as possible to the operating site, and as far as possible away from the pacemaker [48] [49]. If even after these measures are in place, the pacemaker is still affected by the surgical instrumentation then the pacemaker can be converted to a continuous asynchronous pacing mode (VOO) by programming or by placement of a magnet over the device. The magnet must remain in place over the device to maintain asynchronous mode of pacing.

\subsection{Complications and Management}

Again, there is limited clinical information regarding adverse pregnancy outcomes associated with pacemaker usage. In one small study [19], only one patient developed the complication of preeclampsia during the pregnancy. In another case report, a preterm birth at 30 weeks gestation occurred with neonatal acidemia [4]. Lastly, "fetal distress" was reported in a paced gravid patient of unclear etiology, with the subsequent delivery of a healthy infant via cesarean section [34]. None of these cases had similar events, or biologically plausible connections to the pacemakers themselves, suggesting a lack of direct association.

The most common non-obstetrical complication seen with the pacemaker is skin irritation and ulceration at the implantation site due to breast hypertrophy [4] [40]. Therefore, it is important to place the pacemaker in women of reproductive age at a site such as the sub-pectoral region rather then the abdomen or breast areas, which undergo skin changes during pregnancy or may be involved in procedures like cesarean sections. Being mindful of the site of pacemaker placement would also decrease the chance of pacemaker lead dislodgement or fracture, known as Twiddler's syndrome [19]. Other recognized complications, not specifically linked to pregnancy, include chronic pain, battery failure and extra systole [50]-[52].

\section{Conclusion}

Pregnancy in patients with pacemakers is possible but requires a multidisciplinary approach to care. Normal physiologic changes in pregnancy may necessitate antenatal pacing rate adjustments. It may be difficult to distinguish between common pregnancy symptoms and mild degrees of cardiac dysfunction. Other than routine thromboprophylaxis, no other anticoagulation is needed. Pacemaker dependency should be recognized early in pregnancy. Despite cesarean delivery in this case, route of delivery is generally based on obstetric indications. During surgery, bipolar electrocautery should be used to reduce electromagnetic interference and the grounding pad should be placed as far away from the pacemaker as possible. Following the pregnancy, it should be antic- 
ipated that the patient would return to her baseline cardiac status and therefore have the pacemaker settings adjusted accordingly.

\section{References}

[1] Coolen, J., et al. (2011) Permanent Pacemakers in Pregnancy. Clinical and Experimental Obstetrics \& Gynecology, 38, 297-298.

[2] Tateno, S., et al. (2003) Arrhythmia and Conduction Disturbances in Patients with Congenital Heart Disease during Pregnancy: Multicenter Study. Circulation Journal, 67, 992-997. http://dx.doi.org/10.1253/circj.67.992

[3] Eddy, W.A. and Frankenfeld, R.H. (1977) Congenital Complete Heart Block in Pregnancy. American Journal of Obstetrics \& Gynecology, 128, 223-225.

[4] Ginns, H.M. and Hollinrake, K. (1970) Complete Heart Block in Pregnancy Treated with an Internal Cardiac Pacemaker. BJOG: An International Journal of Obstetrics and Gynaecology, 77, 710-712. http://dx.doi.org/10.1111/j.1471-0528.1970.tb03596.x

[5] http://www.nhlbi.nih.gov/health/health-topics/topics/pace/whoneeds.html

[6] Wood, M.A. and Ellenbogen, K.A. (2002) Cardiology Patient Pages. Cardiac Pacemakers from the Patient’s Perspective. Circulation, 105, 2136-2138. http://dx.doi.org/10.1161/01.CIR.0000016183.07898.90

[7] Epstein, A.E., et al. (2008) ACC/AHA/HRS 2008 Guidelines for Device-Based Therapy of Cardiac Rhythm Abnormalities: a report of the American College of Cardiology/American Heart Association Task Force on Practice Guidelines (Writing Committee to Revise the ACC/AHA/NASPE 2002 Guideline Update for Implantation of Cardiac Pacemakers and Antiarrhythmia Devices) Developed in Collaboration with the American Association for Thoracic Surgery and Society of Thoracic Surgeons. Journal of the American College of Cardiology, 51, e1-e62. http://dx.doi.org/10.1016/j.jacc.2008.02.032

[8] Hall, G.A. (2005) Textbook of Medical Physiology. 11th Edition, Saunders, Philadelphia.

[9] Clapp, J.F. and Capeless, E. (1997) Cardiovascular Function Before, During, and After the First and Subsequent Pregnancies. The American Journal of Cardiology, 80, 1469-1473. http://dx.doi.org/10.1016/S0002-9149(97)00738-8

[10] Elkayam, U. and Gleicher, N. (1998) Cardiac Problems in Pregnancy: Diagnosis and Management of Maternal and Fetal Heart Disease. 3rd Edition, Wiley-Liss, Vol. 3: 1.

[11] Brodsky, M.A., Sato, D.A., Oster, P.D., Schmidt, P.L., Chesnie, B.M. and Henry, W.L. (1986) Paroxysmal Ventricular Tachycardia with Syncope during Pregnancy. The American Journal of Cardiology, 58, 563-564. http://dx.doi.org/10.1016/0002-9149(86)90040-8

[12] Upshaw Jr., C.B. (1970) A Study of Maternal Electrocardiograms Recorded during Labor and Delivery. American Journal of Obstetrics Gynecology, 107, 17-27.

[13] Liebson, P.R., Mann, L.I., Evans, M.I., Duchin, S. and Arditi, L. (1975) Cardiac Performance during Pregnancy: Serial Evaluation Using External Systolic Time Intervals. American Journal of Obstetrics Gynecology, 122, 1-8.

[14] Burg, J.R., Dodek, A., Kloster, F.E. and Metcalfe, J. (1974) Alterations of Systolic Time Intervals during Pregnancy. Circulation, 49, 560-564. http://dx.doi.org/10.1161/01.CIR.49.3.560

[15] Rubler, S., Damani, P.M. and Pinto, E.R. (1977) Cardiac Size and Performance during Pregnancy Estimated with Echocardiography. American Journal of Cardiology, 40, 534-540. http://dx.doi.org/10.1016/0002-9149(77)90068-6

[16] Toogood, G. (2007) Pacemaker Therapies in Cardiology. Australian Family Physician, 36, 518-9, 521-4.

[17] Bernstein, A.D., Daubert, J.-C., Fletcher, R.D., Hayes, D.L., Luderitz, B., Reynolds, D.W., et al. (2002) The Revised NASPE/BPEG Generic Code for Antibradycardia, Adaptive-Rate, and Multisite Pacing. Pacing and Clinical Electrophysiology, 25, 260-264. http://dx.doi.org/10.1046/j.1460-9592.2002.00260.x

[18] Escher, D.J. (1973) Types of Pacemakers and Their Complications. Circulation, 47, 1119-1131. http://dx.doi.org/10.1161/01.CIR.47.5.1119

[19] Hidaka, N., Chiba, Y., Fukushima, K. and Wake, N. (2011) Pregnant Women with Complete Atrioventricular Block: Perinatal Risks and Review of Management. Pacing and Clinical Electrophysiology, 34, 1161-1176. http://dx.doi.org/10.1111/j.1540-8159.2011.03177.x

[20] Janower, M.L. (1964) Electrical Pacemakers and Ventricular Arrhythmias. Journal of the American Medical Association, 190, 775. http://dx.doi.org/10.1001/jama.1964.03070210081021

[21] Nora, J.J. and Nora, A.H. (1987) Maternal Transmission of Congenital Heart Diseases: New Recurrence Risk Figures and the Questions of Cytoplasmic Inheritance and Vulnerability to Teratogens. American Journal of Cardiology, 59, 459-463. http://dx.doi.org/10.1016/0002-9149(87)90956-8

[22] Wallis, H. and Thorne, S. (2006) Congenital Heart Disease and Pregnancy. Women's Health, 2, 743-752. 
http://dx.doi.org/10.2217/17455057.2.5.743

[23] Whittemore, R., Hobbins, J.C. and Engle, M.A. (1982) Pregnancy and Its Outcome in Women with and without Surgical Treatment of Congenital Heart Disease. American Journal of Cardiology, 50, 641-651. http://dx.doi.org/10.1016/0002-9149(82)90334-4

[24] Thaman, R., Curtis, S., Faganello, G., Szantho, G.V., Turner, M.S., Trinder, J., et al. (2011) Cardiac Outcome of Pregnancy in Women with a Pacemaker and Women with Untreated Atrioventricular Conduction Block. Europace, 13, 859-863. http://dx.doi.org/10.1093/europace/eur018

[25] Benrey, J. (1991) Indications and Choices in Pacemaker Therapy. Texas Heart Institute Journal, 18, 170-178.

[26] Beckman, C.R.B., Ling, F.W., Barzansky, B.M., Herbert, N.P., Laube, D.W. and Smith, R.P. (2010) Obstetrics and Gynecology. 6th Edition, Lippincott Williams and Wilkins, Philadelphia.

[27] Karavidas, A., Lazaros, G., Matsakas, E., Kouvousis, N., Samara, C., Christoforatou, E. and Zacharoulis, A. (2004) Early Pacemaker Lead Thrombosis Leading to Massive Pulmonary Embolism. Echocardiography, 21, 429-432. http://dx.doi.org/10.1111/j.0742-2822.2004.03078.x

[28] Kinney, E.L., Allen, R.P., Weidner, W.A., Pierce, W.S., Leaman, D.M. and Zelis, R.F. (1979) Recurrent Pulmonary Emboli Secondary to Right Atrial Thrombus around a Permanent Pacing Catheter: A Case Report and Review of the Literature. Pacing and Clinical Electrophysiology, 2, 196-202. http://dx.doi.org/10.1111/j.1540-8159.1979.tb05201.x

[29] Bilge, M., Guler, N. and Eryonucu, B. (1999) Recurrent Pulmonary Emboli and Thrombus Attached to a Permanently Implanted Pacemaker Wire in Pregnancy. Acta Cardiologica, 54, 97-99.

[30] Harvey, R.A. and Champe, P.C. (2012) Lippincott’s Illustrated Reviews: Pharmacology. 5th Edition, Lippincott Williams \& Wilkins, Philadelphia.

[31] Stout, M.J. and Odibo, A.O. (2013) Anticoagulation in Pregnant Patients with Mechanical Heart Valves: Clinical Considerations. Clinics in Laboratory Medicine, 33, 357-365. http://dx.doi.org/10.1016/j.cll.2013.03.021

[32] Chan, W.S., Anand, S. and Ginsberg, J.S. (2000) Anticoagulation of Pregnant Women with Mechanical Heart Valves: A Systematic Review of the Literature. Archives of Internal Medicine, 160, 191-196. http://dx.doi.org/10.1001/archinte.160.2.191

[33] Loftus, C.M. and Committee, A.P. (1996) Neurosurgical Aspects of Pregnancy. In: Loftus, C.M., Ed., Neurological Topics Series, American Association of Neurological Surgeons, Park Ridge, 225.

[34] Middleton, E.B. and Lee, Y.C. (1971) Pregnancy Associated with Cardiac Pacemaker Generator Implanted in Abdominal Wall: A Case Report. Obstetrics Gynecology, 38, 272-275.

[35] Shouse, E.E. and Acker Jr., J.E. (1964) Pregnancy and Delivery in a Patient with External-Internal Cardiac Pacemaker. Obstetrics Gynecology, 24, 817-818.

[36] Kurjak, A. and Chervenak, F.A., Eds. (2006) Textbook of Perinatal Medicine. 2nd Edition, CRC Press, Boca Raton, 2304.

[37] Sornalatha, M. and Arthi, R. (2013) An Algorithm for Extracting Non-Invasive Fetal ECG from the Maternal ECG. International Journal of Engineering Science and Innovative Technology, 2, 302-310.

[38] Kligfield, P., Gettes, L.S., Bailey, J.J., Childers, R., Deal, B.J., Hancock, E.W., et al. (2007) Recommendations for the Standardization and Interpretation of the Electrocardiogram. Journal of the American College of Cardiology, 49, 11091127. http://dx.doi.org/10.1016/j.jacc.2007.01.024

[39] Hunter, S. and Robson, S.C. (1992) Adaptation of the Maternal Heart in Pregnancy. British Heart Journal, 68, $540-543$. http://dx.doi.org/10.1136/hrt.68.12.540

[40] Matorras, R., Diez, J., Saez, M., Montoya, F., Aranguren, G. and Rodriguez-Escudero, F.J. (1991) Repeat Pregnancy Associated with Cardiac Pacemaker. International Journal of Gynecology \& Obstetrics, 36, 323-327. http://dx.doi.org/10.1016/0020-7292(91)90487-P

[41] Mendelson, M.A. (2008) Pregnancy in the Woman with Preexisting Cardiovascular Disease. The Global Library of Women's Medicine. http://dx.doi.org/10.3843/GLOWM.10161

[42] Ng, Y.T., Cheung, M.W. and Hui, Y.L. (1997) Anesthetic Management of a Parturient Implanted with a Permanent Pacemaker-A Case Report. Acta Anaesthesiologica Sinica, 35, 107-111.

[43] Simpson, J. (1993) Anesthesia and the Patient with Co-Existing Heart Disease. Little Brown \& Co, Boston, 474.

[44] Parer, J.T. (2002) Uteroplacental Circulation and Respiratory Gas Exchange. In: Hughes, S.C., Levinson, G. and Rosen, M.A., Eds., Shnider and Levinson's Anesthesia for Obstetrics, 4th Edition, Lippincott Williams \& Wilkins, Philadelphia, 706.

[45] Amikam, S., Abramovici, H., Brandes, J.M., Peleg, H. and Riss, E. (1981) Pregnancy in the Presence of an Implanted Pacemaker. International Surgery, 66, 369-371. 
[46] Baron, J.-F., Decaux-Jacolot, A., Edouard, A., Berdeaux, A. and Samii, K. (1986) Influence of Venous Return on Baroreflex Control of Heart Rate during Lumbar Epidural Anesthesia in Humans. Anesthesiology, 64, 188-193. http://dx.doi.org/10.1097/00000542-198602000-00010

[47] Caramella, J.P., Mentre, B., Jattiot, F., Strouk, R. and Delétang, D. (1987) Reprogrammation d'un stimulateur cardiaque induite par le bistouri électrique. Annales Françaises d'Anesthésie et de Réanimation, 6, 214-216. http://dx.doi.org/10.1016/S0750-7658(87)80084-9

[48] Batra, Y.K. and Bali, I.M. (1978) Effect of Coagulating and Cutting Current on a Demand Pacemaker during Transurethral Resection of the Prostate: A Case Report. Canadian Anaesthetists' Society Journal, 25, 65-66. http://dx.doi.org/10.1007/BF03006788

[49] Mangar, D., Atlas, G.M. and Kane, P.B. (1991) Electrocautery-Induced Pacemaker Malfunction during Surgery. Canadian Journal of Anesthesia, 38, 616-618. http://dx.doi.org/10.1007/BF03008198

[50] Smirnova, L.M., Glukhova, P.A., Pavlova, S.S. and Ivanova, I.G. (1982) Pregnancy and Labor in Patients with Artificial Pacemakers. Akusherstvo I Ginekologiia, 5, 31-34.

[51] Laurens, P., Haiat, R., Gavelle, P., Maurice, P. and Chiche, P. (1976) Isotop Cardiac Pacemaker during Pregnancy. 3 Cases. La Nouvelle Presse Médicale, 5, 2997-3000.

[52] Jaffe, R., Gruber, A., Fejgin, M., Altaras, M. and Ben-Aderet, N. (1987) Pregnancy with an Artificial Pacemaker. Obstetrical \& Gynecological Survey, 42, 137-139. http://dx.doi.org/10.1097/00006254-198703000-00002 
Scientific Research Publishing (SCIRP) is one of the largest Open Access journal publishers. It is currently publishing more than 200 open access, online, peer-reviewed journals covering a wide range of academic disciplines. SCIRP serves the worldwide academic communities and contributes to the progress and application of science with its publication.

Other selected journals from SCIRP are listed as below. Submit your manuscript to us via either submit@scirp.org or Online Submission Portal.
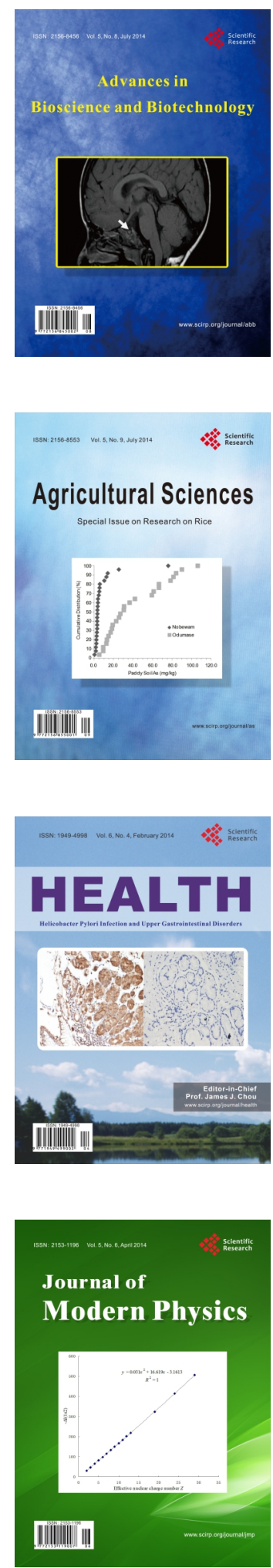
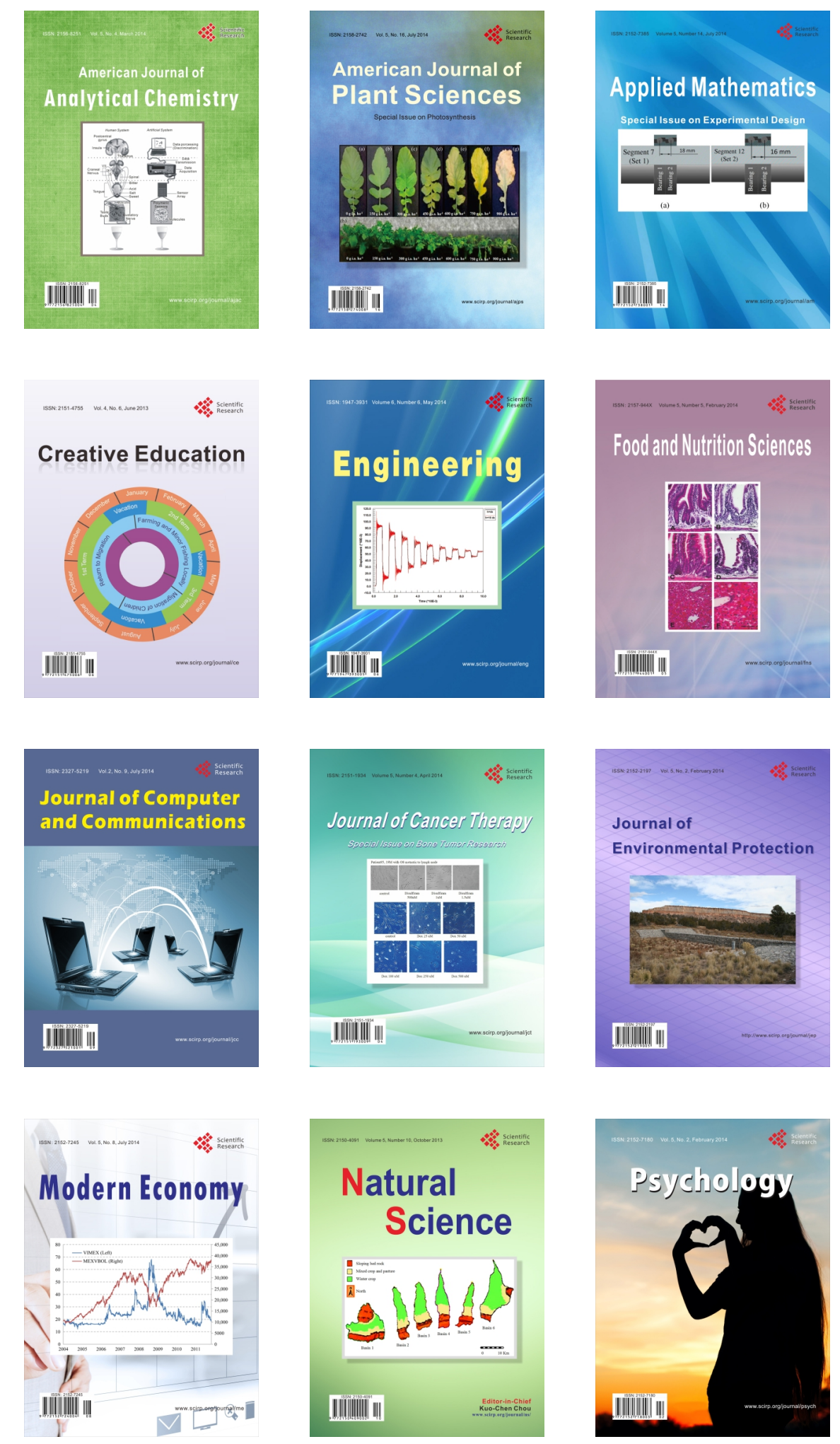